\title{
Parametric Optimization of Ball Burnishing Process Parameter for Hardness of Aluminum Alloy 6061
}

\author{
P. N. Patel ${ }^{1}$, N.B. Patel ${ }^{2}$, T. M. Patel ${ }^{3}$ \\ ${ }^{1}$ (ME Scholar, MEC, Basna) \\ ${ }^{2}$ (Assistant Professor, MEC Basna) \\ ${ }^{3}$ (Associate Professor, LDRP ITR, Gandhinagar)
}

\begin{abstract}
These study deals with optimization of newly design ball burnishing tool is used carried out experiment on conventional lathe machine with burnishing process parameters using taguchi analysis method. The work piece and ball materials used is Aluminum Alloy 6061 and high chromium high carbon with 8mm diameter. The levels of input process parameters are selected on basis of one factor at a time experiment are burnishing force, burnishing feed, burnishing speed and number of passes. The response parameters is hardness. The optimal parameters for hardness are as follows: burnishing speed 250 RPM, burnishing feed rate 0.06 $\mathrm{mm} / \mathrm{rev}$, burnishing force, $8 \mathrm{Kgf}$, No. of passes 5.
\end{abstract}

Keywords: - ball burnishing tool, burnishing parameters, hardness, optimization, taguchi.

\section{INTRODUCTION}

In today's manufacturing industry, special attention is given on surface finish along with dimensional accuracy and geometrical tolerance. Comparing with other finishing process such as grinding, honing, burnishing is chip less process. Burnishing is a cold working surface finishing process which is carried out on material surfaces to induce compressive residual stresses and enhance surface qualities. A burnishing tool typically consists of a hardened sphere which is pressed onto across the part being processed which results in plastic deformation of asperities into valleys. In burnishing process in which initial asperities are compressed beyond yield strength against load. The surface of the material is progressively compressed, then plasticized as resultant stresses reach a steady maximum value and finally wiped a superfine finish.

The burnishing process, shown in Fig. 1 is based on the rolling movement of a tool (a ball or a roller) against the workpiece surface, a normal force being applied at the tool. As soon as the yield point of the workpiece material is exceeded, plastic flow of the original asperities takes place. This phenomenon leads to a smoother surface. At the same time, compressive stresses are induced in the surface layer, followed by strain hardening and a series of beneficial effect on mechanical properties. Burnishing can improve both the surface strength and roughness. The increase of surface strength mainly serves to improve fatigue resistance under dynamic loads.

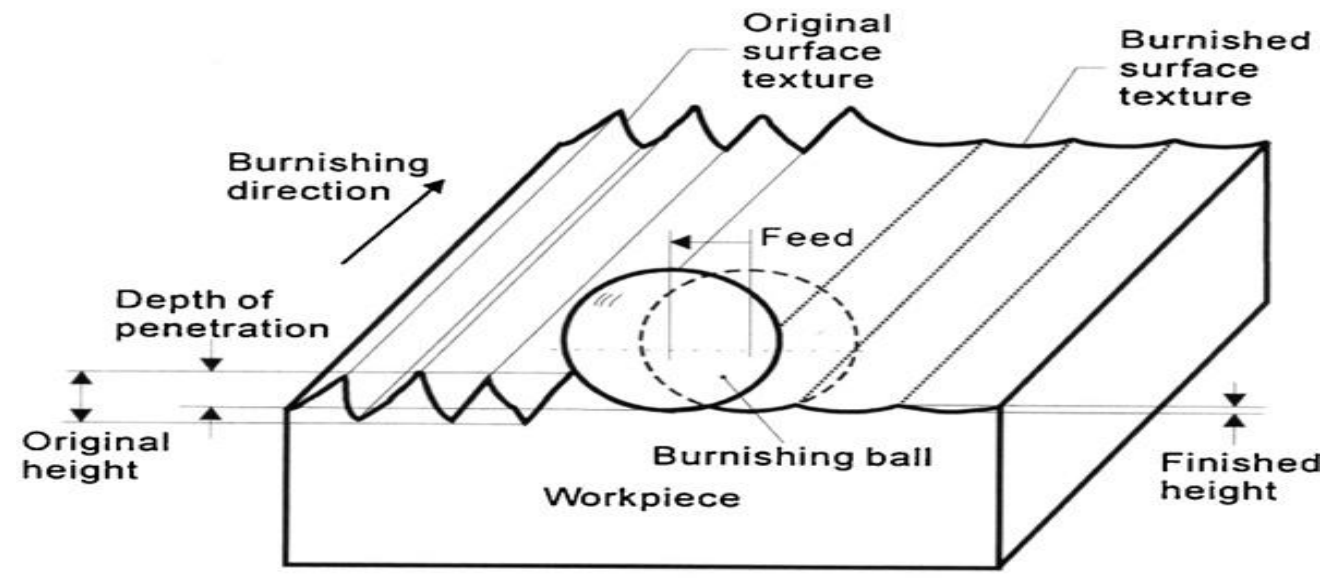

Fig. 1 Schematic diagram of the ball burnishing process. ${ }^{8}$

The literature review indicates that earlier investigations concentrated on the effect of the ball burnishing process dealing mostly with surface finish and surface hardness with little focus on optimization of the burnishing parameters. M.H. El-Axira et al. used simple newly designed internal ball burnishing tool to burnish the internal machined surfaces. They carried out an experiment on AA 2014 with having diameter 
$100 \mathrm{~mm}$ and analyzed effect of four internal ball burnishing parameters; namely, burnishing speed, feed rate, depth of penetration and number of passes on surface roundness and surface micro hardness using Response surface method (RSM) [1]. Aysun Sagbas et al. experiment on AA7178 and studied the effect of the main burnishing parameters burnishing force, feed rate and number of passes on surface hardness on CNC machine using full factorial design, analysis of variance (ANOVA) and taguchi's L9 orthogonal array analysis of S/N ratio with larger is better condition [2]. R. Aviles et al. analyzed improvement fatigue strength of AISI 1045 normalized steel with after ball burnishing with ceramic ball of $6 \mathrm{~mm}$ diameter pressed hydraulically by means of pump at max 40MPa. By using hydrostatic burnishing tools the ball head can freely move 6-8 mm .After burnishing surface roughness improves from $0.68-0.12 \mu \mathrm{m}$ and hardness increases by up to $20 \%$. They determine that the bending fatigue limit is increased by $21.25 \%$ [3] R. Sadeler et.al investigated the fatigue behaviour of AISI 1045 steel at different Pressures varied from 100 to 300 bar. The hard steel HG6 ball of $6 \mathrm{~mm}$ diameter is hydrostatically forced toward workpiece. They conclude that roughness improve with increasing pressure from $0.299 \mu \mathrm{m}$ to $0.099 \mu \mathrm{m}$ and also enhance both fatigue limit from 332 to 362 after 300 bar pressure [4]. P. S. Dabeer et al. Carried out experiment on brass material on lathe machine with high chromium high carbon ball having varying diameter with range of $6-10 \mathrm{~mm}$. RSM central composite second order rotatable design used to develop mathematical model to correlate effect of burnishing parameter on material, using ANOVA techniques and F-test effects on surface roughness[5]. Pavan Kumar et al. Design and develop ball burnishing tool. Ball burnishing adapter with roller burnishing interchanging adapter type tool. The ball adapter has made up of EN 8 material, Design of square casing made of mild steel and has dimensions of 150 $\mathrm{mm} * 25 \mathrm{~mm} * 25 \mathrm{~mm}$. Specification of spring: $\mathrm{D}=25 \mathrm{~mm} \mathrm{~d}=3 \mathrm{~mm}$. The force is measured by means of spring deflections in the tool [6]. Prasad Bhardwaj et al. investigate effect of burnishing parameters on the AISI D3 tool steel material using burnishing tool having carbide ball of 8 and $10 \mathrm{~mm}$ diameter, which is supported by two balls of 4mm diameter. (FEM) finite element method used for analysis purpose based software DEFORM-2. They conclude that hardness, residual stress, out of roundness also improves along with surface roughness [7].

The present work, aims at systematically studying the effect of process parameters like speed, feed, burnishing force, number of passes and their interactions on hardness for the component surface produced by newly developed ball burnishing tool. One factor at a time is carried out to identify the range of parameters used for experiment. Experiments will be planned according to statistical design of experiments using taguchi's orthogonal array method, signal to noise ratio method is used to improve the reliability of results.

\section{EXPERIMENTAL DETAILS}

Experiments are conducted on a HMT lathe machine. A simple new burnishing tool is designed to carry out the experimental work on Aluminum Alloy 6061 using high chromium high carbon ball of $8 \mathrm{~mm}$ diameter. The ball holder is supported elastically by a pre-calibrated spring, which could apply the required force when pressed onto the workpiece surface. The use of the spring is important for reducing sticking due to friction between the ball and the workpiece. The amount of spring compression with relation to the applied vertical force $\left(\mathrm{P}_{\mathrm{Y}}\right)$.

The burnishing tool design consist of following components as shown in Fig. 2

- Adapter

- $\quad$ Spring Loaded End

- Cover

- Square Casing

- Force Controlling Pin

- Ball of $8 \mathrm{~mm}$ Diameter

- Spring

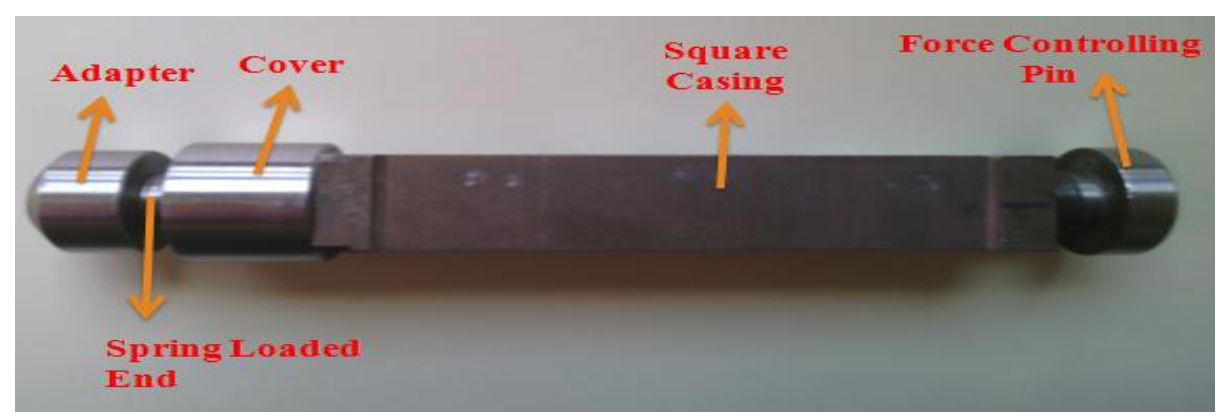

Fig. 2 Ball Burnishing Tool 


\subsection{Design of Ball Burnishing Tool}

To design burnishing tool, it is essential to calculate the normal burnishing force for given condition.

2.1.1 Normal Burnishing Force: $\mathrm{P}_{\mathrm{Y}}$ $\mathrm{P}_{\mathrm{Y}}=\Pi \varepsilon \mathrm{HR}^{2}$

Where $\varepsilon=$ Relative depth of penetration $=0.002-0.003$

$\mathrm{R}=$ Ball Radius $=4 \mathrm{~mm}$

$\mathrm{H}=$ Vickers Hardness of Work Material $=107$

$\mathrm{P}_{\mathrm{Y}}=\Pi \varepsilon \mathrm{HR}^{2}$

$\mathrm{P}_{\mathrm{Y}}=(3.14) *(0.025) *(107) *(4)^{2}$

$\mathrm{P}_{\mathrm{Y}}=13.4 \mathrm{Kgf}=13 \mathrm{Kgf}$

\subsubsection{Spring Stiffness [11]}

The spring used in these work is of EN 9 material, which helps to measures burnishing force by means of spring deflections in the square casing.

Length of Spring $\mathrm{L}=150 \mathrm{~mm}$

Spring Diameter $\mathrm{D}=17 \mathrm{~mm}$

Spring Wire Diameter $\mathrm{D}=2.5 \mathrm{~mm}$

Number of Turns $\mathrm{N}=\mathrm{n}+2=28+2=30$

Solid Length $\mathrm{Ls}=\mathrm{n} * \mathrm{~d}=75 \mathrm{~mm}$

Deflection of spring is provided by rotating the Force Controlling Pin

Maximum Deflection of spring $=20 \mathrm{~mm}$

Normal Burnishing Force $\mathrm{P}_{\mathrm{Y}}=13 \mathrm{Kgf}=127.4 \mathrm{~N}$

Stiffness $\mathrm{K} 1=\mathrm{P}_{\mathrm{Y}} / \mathrm{D}=127.4 / 20 * 10-3=6370 \mathrm{~N} / \mathrm{M}$

$1.5 \mathrm{~mm}$ Rotation of Force Controlling Pin apply $1 \mathrm{Kgf}$ force

So, available Stiffness $\mathrm{K}=9.8 / 1.5 * 10-3=6533 \mathrm{~N} / \mathrm{M}$

As $(\mathrm{K} 1<\mathrm{K})$, The Design of spring is safe.

\subsection{Test Materials}

The work pieces used is Aluminum Alloy 6061 which is received as rounded bars of 40-mm diameter. The bars are cut to appropriate lengths $(270-310 \mathrm{~mm})$ and turned to a diameter of $38 \mathrm{~mm}$. Each workpiece is divided into 8 regions of $25 \mathrm{~mm}$ by slot of $10 \mathrm{~mm}$ length and $2 \mathrm{~mm}$ depth.

\subsection{Measuring Instrument}

The hardness (BHN) is measured using hardness tester SAMSONIC MHT 170. The tester ball rounded type and the impact tip is of tungsten carbide with $3 \mathrm{~mm}$ dia. The hardness measurement is shown in Fig. 3 .

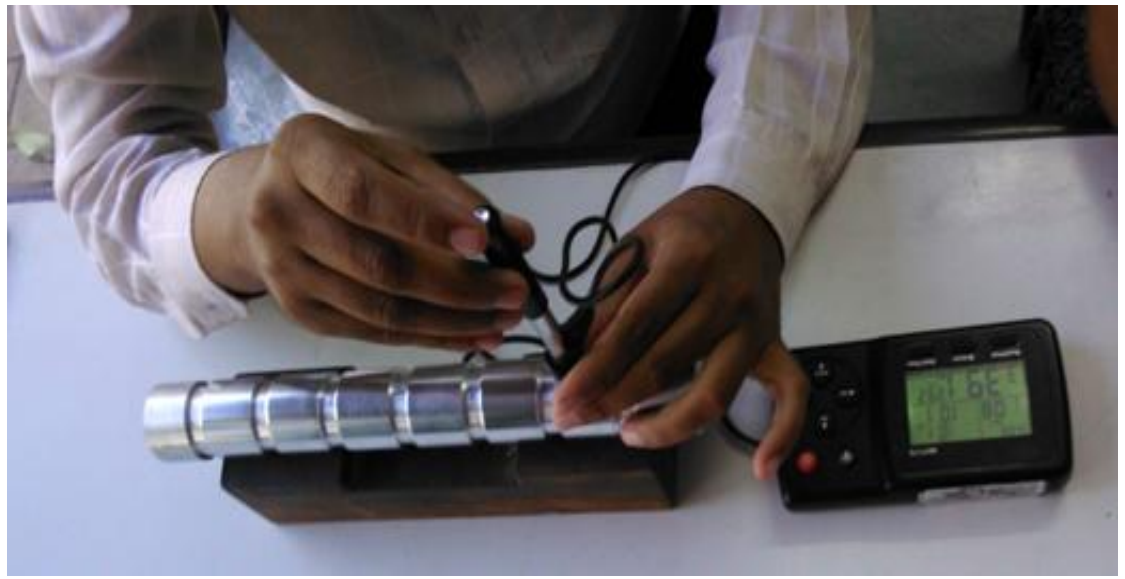

Fig. 3 Hardness Measurement

\section{RESULT AND DISCUSSION}

Experiments are planned according to Taguchi's analysis with L25 orthogonal array using Minitab 16 software as shown in Table. 2. The ranges of the burnishing parameter used in this experiment shown in Table. 1 are decided on basis of one factor at a time experiment approach. The burnishing operation is shown in Fig. 4. 
Table. 1 Factor and Levels

\begin{tabular}{|l|c|c|c|c|c|}
\hline \multicolumn{1}{|c|}{ Factors } & Level 1 & Level 2 & Level 3 & Level 4 & Level 5 \\
\hline Speed (RPM.) & 63 & 125 & 250 & 350 & 500 \\
\hline Feed (mm/rev) & 0.06 & 0.12 & 0.18 & 0.24 & 0.30 \\
\hline Force (Kgf) & 2 & 4 & 6 & 8 & 10 \\
\hline Passes & 1 & 2 & 3 & 4 & 5 \\
\hline
\end{tabular}

Table. 2 Orthogonal Arrays L 25

\begin{tabular}{|c|c|c|c|c|c|}
\hline Exp No & Speed (RPM) & Feed (mm/rev) & Force (Kgf) & Passes & Hardness(BHN) \\
\hline 1 & 63 & 0.06 & 2 & 1 & 110 \\
\hline 2 & 63 & 0.12 & 4 & 2 & 108 \\
\hline 3 & 63 & 0.18 & 6 & 3 & 109 \\
\hline 4 & 63 & 0.24 & 8 & 4 & 104 \\
\hline 5 & 63 & 0.30 & 10 & 5 & 103 \\
\hline 6 & 125 & 0.06 & 4 & 3 & 116 \\
\hline 7 & 125 & 0.12 & 6 & 4 & 115 \\
\hline 8 & 125 & 0.18 & 8 & 5 & 116 \\
\hline 9 & 125 & 0.24 & 10 & 1 & 93 \\
\hline 10 & 125 & 0.30 & 2 & 2 & 92 \\
\hline 11 & 250 & 0.06 & 6 & 5 & 123 \\
\hline 12 & 250 & 0.12 & 8 & 1 & 120 \\
\hline 13 & 250 & 0.18 & 10 & 2 & 103 \\
\hline 14 & 250 & 0.24 & 2 & 3 & 100 \\
\hline 15 & 250 & 0.30 & 4 & 4 & 98 \\
\hline 16 & 350 & 0.06 & 8 & 2 & 111 \\
\hline 17 & 350 & 0.12 & 10 & 3 & 109 \\
\hline 18 & 350 & 0.18 & 2 & 4 & 111 \\
\hline 19 & 350 & 0.24 & 4 & 5 & 106 \\
\hline 20 & 350 & 0.30 & 6 & 1 & 86 \\
\hline 21 & 500 & 0.06 & 10 & 4 & 117 \\
\hline 22 & 500 & 0.12 & 2 & 5 & 116 \\
\hline 23 & 500 & 0.18 & 4 & 1 & 98 \\
\hline 24 & 500 & 0.24 & 6 & 2 & 94 \\
\hline 25 & 500 & 0.30 & 8 & 3 & 92 \\
\hline
\end{tabular}

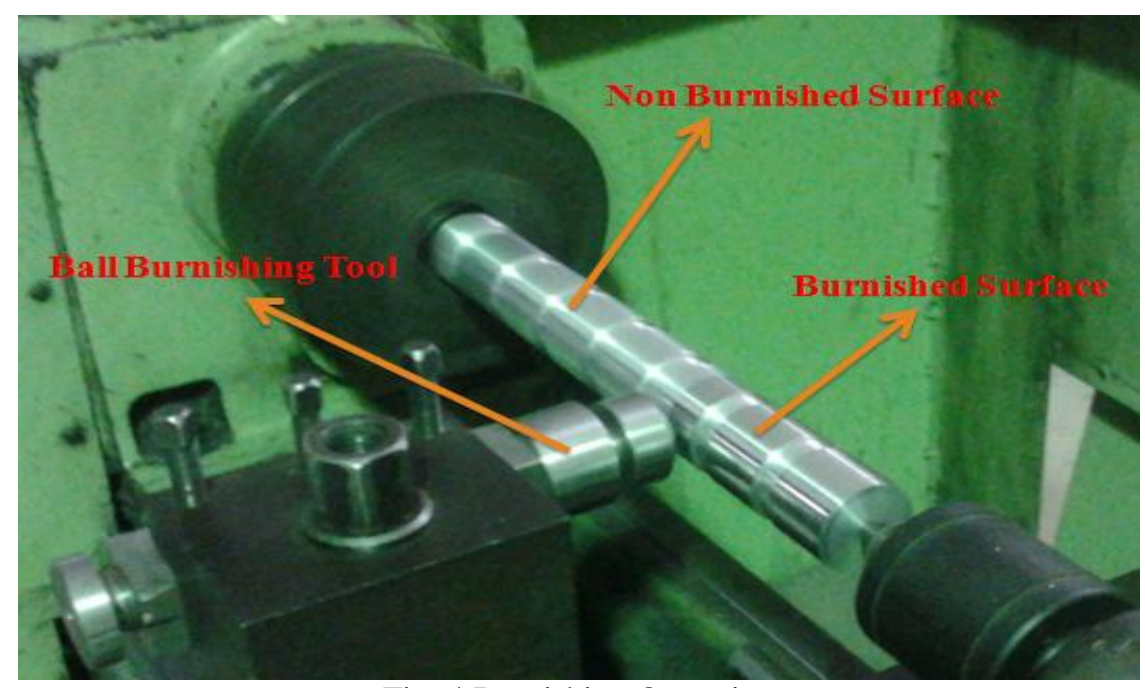

Fig. 4 Burnishing Operation 


\subsection{Taguchi Analysis}

The experimental results are transferred to a signal-to-noise $(\mathrm{S} / \mathrm{N})$ ratio with the-larger-the-better category is used to calculate the $\mathrm{S} / \mathrm{N}$ ratio quality characteristics of hardness. In this analysis the response table of means and signal to noise ratio as shown in Table. 3 have same rank order and plot the graph of main effect plot for means and signal to noise ratio.

Table. 3 Response Table

\begin{tabular}{|c|c|c|c|c|c|c|c|c|c|}
\hline \multicolumn{4}{|c}{ Means } & \multicolumn{4}{c|}{ Signal To Noise Ratio (S/N Ratio) } \\
\hline Level & Speed & Feed & Force & Passes & Level & Speed & Feed & Force & Passes \\
\hline 1 & 106.80 & 115.40 & 105.80 & 101.20 & 1 & 40.57 & 41.24 & 40.46 & 40.06 \\
\hline 2 & 106.40 & 113.60 & 105.20 & 101.40 & 2 & 40.49 & 41.10 & 40.42 & 40.11 \\
\hline 3 & 108.80 & 107.40 & 105.40 & 105.20 & 3 & 40.69 & 40.61 & 40.38 & 40.41 \\
\hline 4 & 104.60 & 99.40 & 108.80 & 109.00 & 4 & 40.35 & 39.94 & 40.68 & 40.73 \\
\hline 5 & 103.40 & 94.20 & 105.00 & 112.80 & 5 & 40.24 & 39.46 & 40.40 & 40.03 \\
\hline Delta & 5.40 & 21.20 & 3.60 & 11.40 & Delta & 0.45 & 1.77 & 0.30 & 0.97 \\
\hline Rank & 3 & 1 & 4 & 2 & Rank & 3 & 1 & 4 & 2 \\
\hline
\end{tabular}

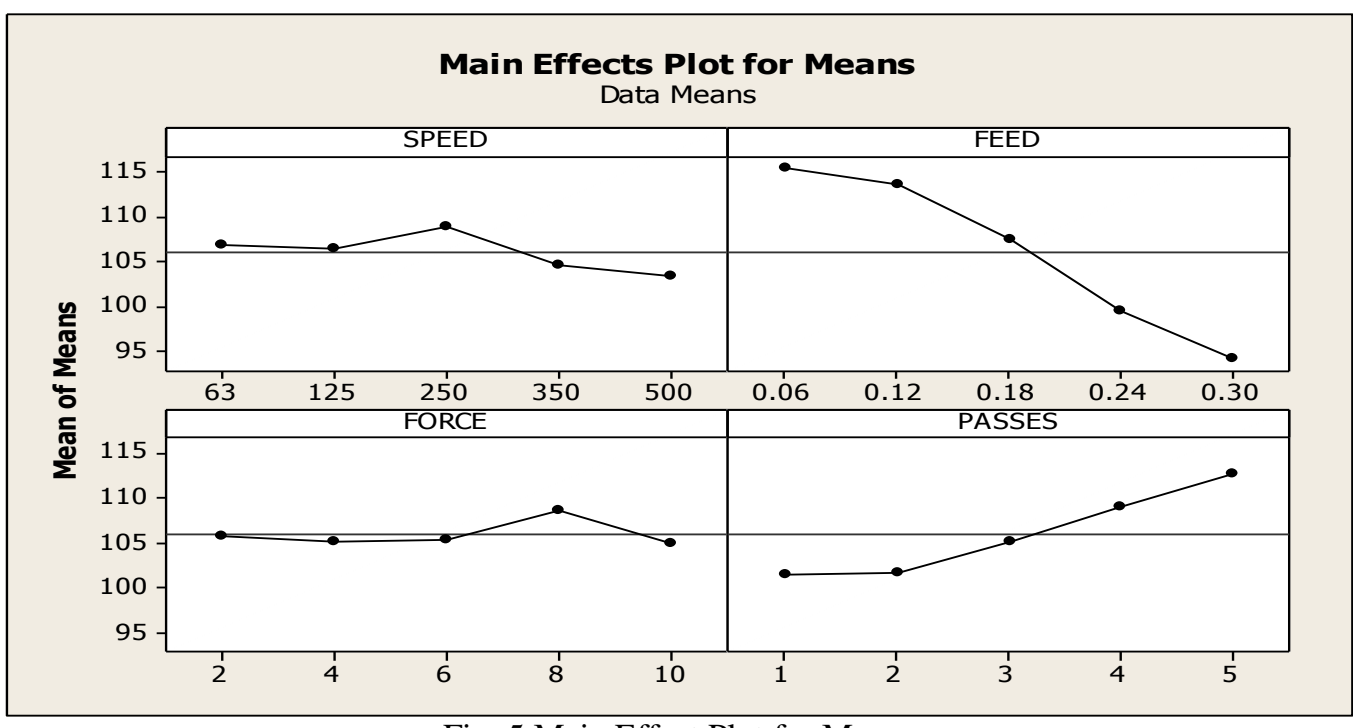

Fig. 5 Main Effect Plot for Means

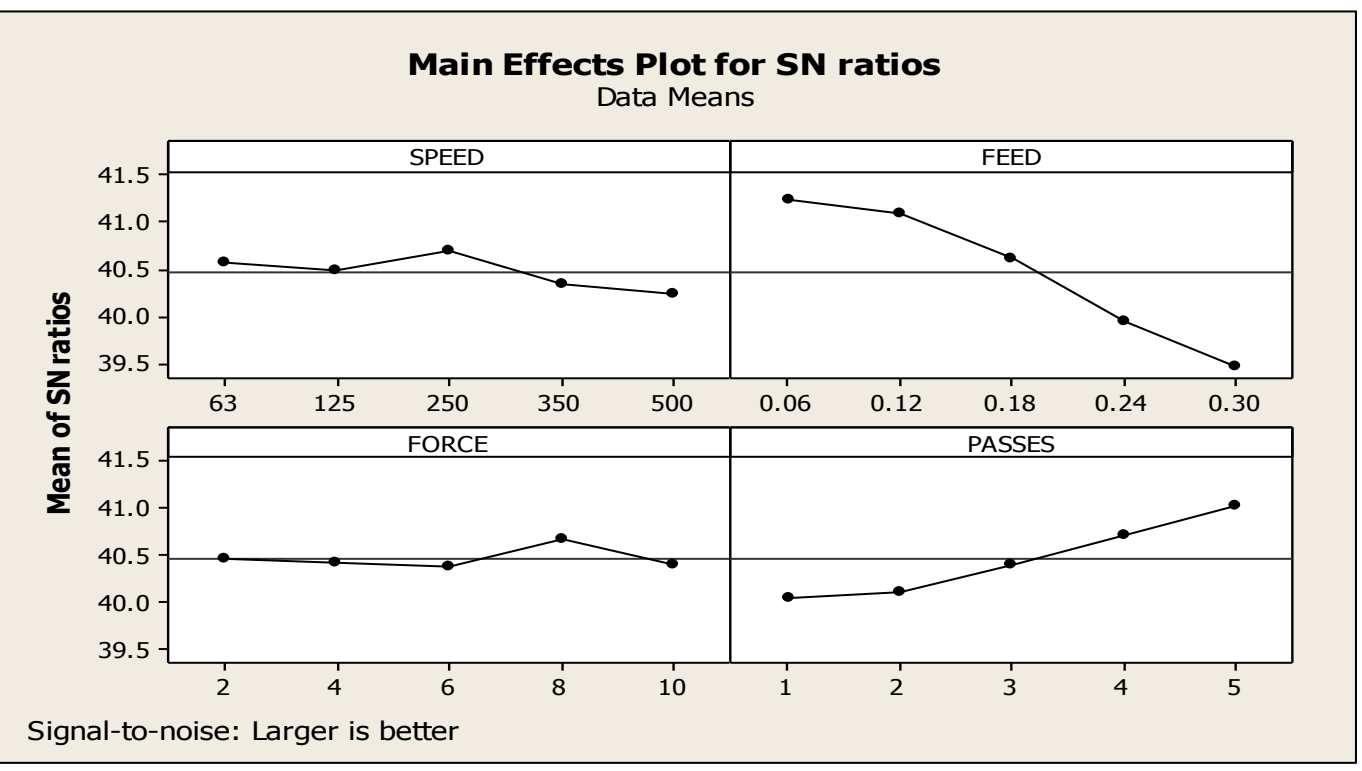

Fig. 6 Main Effect Plot for S/N Ratio. 
The optimal parameter combination for maximum hardness is obtained by analysis of the $\mathrm{S} / \mathrm{N}$ ratio from Fig. 5 and Fig. 6 that the optimal parameters for hardness are as follows: burnishing speed 250 RPM, burnishing feed rate $0.06 \mathrm{~mm} / \mathrm{rev}$, burnishing force, $8 \mathrm{Kgf}$, No. of passes 5 . The conformation test is carried out with this optimum parameter as shown in Table. 4 and the hardness obtained is higher than the maximum value of hardness obtained by experiments carried out on basis of array generated.

Table. 4 Experimented Results at Predicted Optimum Level

\begin{tabular}{|c|c|c|c|c|}
\hline Speed & Feed & Force & Passes & BHN \\
\hline 250 & 0.06 & 8 & 5 & 126 \\
\hline
\end{tabular}

\section{CONCLUSION}

- Hardness increase with increase in speed up to 250 RPM and further gets decreases either increases in speed. It's due to possible chattering of the burnishing tool and the increase in temperature, which increases the possibilities of material transformation between the burnishing ball workpiece interfaces start to have a decisive effect.

- Hardness decreases with increasing feed. When feed rate is low the distance between successive traces will be small.

- Hardness increase up to $8 \mathrm{Kgf}$ force and start decreases beyond it. As this force increases, the penetration depth of the ball inside the metallic surface will be increased, leading to a smoothing-out of the metallic surface, until this surface starts to show some deterioration, the latter being caused by the flaking of the surface due to the high work-hardening induced into the surface by the increase in the amount of plastic deformation as the burnishing force increases.

- Hardness increases with increasing in number of passes. Similarly to the effect of burnishing force, after a particular number of passes, the surface layer becomes highly work-hardened, causing flaking to occur.

\section{REFERENCES}

[1] M. H. El-Axir, O. M. Othman and A. M. Abodiena, study on the inner surface finishing of aluminium alloy 2014 by ball burnishing process, journal of materials processing technology Vol 202, 2008, 435442.

[2] Aysun Sagbas, Funda Kahraman, Determination of optimal ball burnishing parameters for surface hardness, Professional article / Strokovni lanek MTAEC 9, Vol 43(5), 2009, 271

[3] R. Avilés, J, Albizuri, A. Rodríguez, L.N. López ,de Lacalle, Influence of low-plasticity ball burnishing on the high-cycle fatigue strength of medium carbon AISI 1045 steel, International Journal of Fatigue, Vol 55, 2013, 230-244

[4] R. Sadeler, M. Akbulut,S. Atasoy, Influence of mechanical (ball burnishing) surface treatment on fatigue behaviour of AISI 1045 steel, Kovove Mater. Vol 51 2013, 31-35.

[5] P. S. Dabeer and G. K. Purohit, Determination of surface roughness by ball burnishing process using factorial techniques, , World Academy of Science, Engineering and Technology, Vol 79 2013, 1032-1035.

[6] Mr. Pavan Kumar and Purohit G K, Design and Development of Ball Burnishing Tool, International Journal of Engineering Research and Technology, Volume 6, Number 6 (2013), 733-738.

[7] Prasad Bhardwaj, Welsoon Wilson, Vinav Abraham, An investigation of ball burnishing process on AISI D3 tool steel using finite element analysis

[8] Low Plasticity Burnishing, Wikipedia. 